\title{
RISK FACTORS AND COMORBIDITY IN PATIENTS WITH ATRIAL FIBRILLATION AND ISCHEMIC HEART DISEASE
}

\author{
Yuliia Kushnir \\ Department of Internal Medicine 2 \\ SI «Dnipropetrovsk Medical Academy of the Ministry of Health of Ukraine» \\ 9 Vernadskogo str., Dnipro, Ukraine 49044 \\ dr.yulia.kushnir@gmail.com
}

\begin{abstract}
The aim of the study was to evaluate the risk factors and the incidence of comorbidity in patients with coronary heart disease, depending on the presence of atrial fibrillation.

Materials and methods of research: a retrospective analysis of 222 histories of illnesses of patients with coronary heart disease who undergo inpatient treatment, aged from 39 to 88 years, has been conducted. Depending on the presence of atrial fibrillation, all patients were divided into 2 groups: group 1 (main) - patients with ischemic heart disease with atrial fibrillation ( $\mathrm{n}=105)$, group 2 (comparison) - patients with ischemic heart disease without atrial fibrillation $(\mathrm{n}=117)$.

Results. In the group of patients without AF, the proportion of persons with inherited exacerbations of IHD was $64.29 \%$, while in the main group $-25.0 \%$, the differences did not reach the statistically significant level, but this relationship is confirmed by the results of the rank correlation analysis - between the presence AP and heredity revealed a significant weak feedback $-\mathrm{c}=-0.21$ $(p<0.05)$. The diseases that were observed in the examined patients with coronary artery disease present acute stroke, angina pectoris, acute myocardial infarction, hypertension, diabetes, pathology of the kidneys and the thyroid gland, diastolic dysfunction and obesity. The groups differed in the proportion of patients with stroke - in the group with AF, it was significantly ( $\mathrm{p}=0.002)$ higher $-23.81 \%$, in compare to $8.55 \%$ in the comparison group.

Conclusions: The presence of atrial fibrillation in patients with coronary heart disease is associated with a high degree of comorbidity. First of all, with the combination of IHD and atrial fibrillation, a high incidence of hypertension, diabetes mellitus, obesity, acute stroke, kidney disease and thyroid gland is established.
\end{abstract}

Keywords: atrial fibrillation, ischemic heart disease, comorbid pathology, risk factors.

\section{Introduction}

At present, atrial fibrillation (AF) is one of the most common forms of arrhythmias, which often leads to acute cerebrovascular disruption and has a negative social significance $[1,2]$.

According to statistics, every fifth case of stroke is due to the presence of atrial fibrillation $[3,4]$. In this case, ischemic strokes in this type of arrhythmias often have fatal consequences, and those surviving patients have consequences with severe disability [5].

It is known, that spread of comorbidity is connected with age [6]. According to literature, with age, the prevalence of atrial fibrillation is also increasing: almost $10 \%$ of people over the age of 80 undergo AF; for those who have reached the age of 94 this figure is up to $25 \%$ [7, 8]. The study of risk factors and comorbidity in patients with atrial fibrillation of non-valvular genesis requires a detailed analysis, since it has clinical significance for the prevention and treatment of this category of patients.

\section{Aim of the research}

To evaluate the risk factors and the incidence of comorbidity in patients with ischemic heart disease, depending on the presence of atrial fibrillation.

\section{Materials and methods of the research}

A retrospective analysis of 222 histories of illnesses of patients with ischemic heart disease (IHD) undergoing in-patient treatment on the basis of the "Regional Clinical Hospital named after I. I. Mechnikov" during 2015-2016, aged from 39 to 88 years.

Depending on the presence of atrial fibrillation, all patients were divided into 2 groups:

Group 1 (main) - patients with ischemic heart disease with atrial fibrillation $(n=105)$.

Group 2 (comparison) - patients with ischemic heart disease without atrial fibrillation ( $\mathrm{n}=117)$. 
From all patients were collected anamnestic data, physical and laboratory-instrumental tests (clinical and biochemical blood tests, general urine analysis, electrocardiogram registration, radiography of the chest, ultrasound examination of the abdominal cavity). All patients were measured anthropometric data with the calculation of the body mass index (BMI) according to the standard formula [9]. To evaluate the function of the kidneys were performed the determination of creatinine and the calculation of glomerular filtration rate (GFR) according to the MDRD formula [10] according to the recommendations of the American National Federation of Nephrology [5, 10]. In order to evaluate the hemodynamic parameters, patients underwent pre-pleural cardiac examination of the heart using the standard method [9]. In the presence of indications, the patient was monitored with the Holter's method. The functional state of the thyroid gland was determined by the evaluation of thyroid hormones with the subsequent consultation of the endocrinologist.

For statistical processing of the research material, the following biostatistical methods were used: verification of the normality of the distribution of quantitative attributes in separate groups of comparison by the Shapiro-Wilka criterion; estimation of the reliability of the mean difference for quantitative signs with abnormal distribution by the Mann-Whitney criterion (U); correlation analysis with calculation of Spearman rank correlation coefficients $(\rho)$. To describe the selective abnormal distribution of quantitative signs, the median (Me) and the interquartile scale (25\%, $75 \%$ ) were used. For the calculated relative values (P), the average error of the relative magnitude $(\mathrm{mR})$ and $95 \%$ confidence intervals were determined by the Wilson method with the correction for continuity. For the analysis of the relationships between different features, a correlation analysis was used to calculate the Spirman rank correlation coefficients $(\rho)$ [11].

The critical value of the statistical significance level when checking the null hypotheses was taken as 0.05 ( $5 \%$ ). When the value of $\mathrm{p}>0.05$ was obtained, the difference between the indices was considered to be unreliable [12].

Statistical processing of the results was performed using the STATISTICA 6.1 software (StatSoftInc., Serial number AGAR909E415822FA), Excel 2010, and the MedCalcStatistical Software trial version 17.4 software package. (MedCalcSoftwarebvba, Ostend, Belgium).

\section{Results of the research}

The general characteristics of the study groups are shown in Table $\mathbf{1 .}$

Since the abnormal distribution of quantitative signs was observed in the overwhelming majority (over $80 \%$ ) of indicators for describing the central trend of data, the median and the interquartile $\mathrm{Me}(25 \%, 75 \%)$ were used.

Analysis on the homogeneity of the study groups showed that there were no significant differences in the distribution of patients in groups depending on sex, anthropometric indicators (average height, weight, BMI), risk factors (heredity, smoking) ( $\mathrm{p}>0.05$ ), indicating their comparability and allows comparisons of other parameters.

The presence of statistically significant differences according to age characteristics was determined $(\mathrm{p}<0.001)$ : in the group with AF, on average, older patients (average age 65.0 (59.0; $72.0)$ ) compared with the group without AF $(60.0(53.0 ; 69.0))$. The proportion of persons over the age of 60 in the main group is $68.57 \%$, in the comparison group $-48.72 \%(p=0.003)$. The inverse weak link between the presence of AF (group) and age is the Spearman correlation coefficient $\mathrm{c}=-0.23(\mathrm{p}<0.05)$.

The proportion of persons with BMI greater than 30 is higher in the group without atrial fibrillation (36.46\% versus $27.27 \%$ in the AF group) without statistically significant differences.

In the group of patients without $\mathrm{AF}$, the proportion of persons with inherited exacerbations of IHD was $64.29 \%$, while in the main group - $25.0 \%$, the differences did not reach the statistically significant level, but this relationship is confirmed by the results of the rank correlation analysis - between the presence AF and heredity revealed a significant weak feedback $\mathrm{c}=-0.21(\mathrm{p}<0.05)$.

The diseases observed in the examined patients with ischemic heart disease are acute stroke, angina pectoris, acute coronary syndrom (ACS), hypertension (HT), diabetes mellitus (DM), kidney and thyroid pathology, diastolic dysfunction (DD) and obesity (Table 2). 
Table 1

The general characteristics of the study groups with IHD

\begin{tabular}{ccccc}
\hline Indicators & Totally observed & Group with AF & Group without AF & p \\
\hline Number & $222(100.0 \%)$ & $105(47.3 \%)$ & $117(52.7 \%)$ & - \\
man & $55(52.38 \%)$ & $59(50.43 \%)$ & $59(50.43 \%)$ & $0.771^{*}$ \\
female & $50(47.62 \%)$ & $58(49.57 \%)$ & $58(49.57 \%)$ & - \\
Min - max & & Age & & $39.0-84.0$ \\
Average age Me $(25 \% ; 75 \%)$ & $64.0(55.0 ; 70.0)$ & $65.0(59.0 ; 72.0)$ & $60.0(53.0 ; 69.0)$ & $<\mathbf{0 . 0 0 1}^{\#}$
\end{tabular}

Structure by age, n ( \%)

$\begin{array}{llll}\text { Age }<60 \text { years } & 93(41.89 \%) & 33(31.43 \%) & 60(51.28 \%) \\ \text { Age }>60 \text { years } & 129(58.11 \%) & 72(68.57 \%) & 57(48.72 \%)\end{array}$

Anthropometric indicators, $\mathrm{Me}(25 \% ; 75 \%)$

$\begin{array}{lcccc}\text { Height }(\mathrm{cm}) & 170.0(162.0 ; 178.0) & 170.0(160.0 ; 180.0) & 168.0(163.0 ; 176,0) & 0.446^{\#} \\ \text { Weight }(\mathrm{kg}) & 82.0(70.0 ; 97.0) & 81.0(70.0 ; 95.0) & 82.5(72.0 ; 98.0) & 0.492^{\#}\end{array}$

$\operatorname{Min}-\max$

Average BMI Me

$(25 \% ; 75 \%)$

$\mathrm{BMI}>30, \mathrm{n}(\%)$

n (data available)

Heredity (data available)

Heredity (observed)

$\mathrm{n}($ data available $)$

Smoking (data available)

Smoking (observed)
BMI

$19.53-42.2$

$20.4-47.9$

$29.05(23.88 ; 33.31)$

$28.55(23.44 ; 32.05)$

$29.48(24.79 ; 34.40)$

$0.146^{\#}$

$53(23.87 \%)$

$18(17.14 \%)$

$35(29.91 \%)$

0.026 *

Risk factors, $\mathrm{n}(\%)$

26

12

14

$\begin{array}{cc}12(46.15 \%) & 3(25.0 \%) \\ 12(5.41 \%) & 3(2.86 \%) \\ 20 & 8 \\ 10(4.5 \%) & 2(1.9 \%) \\ 10(4.5 \%) & 2(1.9 \%)\end{array}$

$9(64.29 \%)$

$9(7.69 \%)$

12

$8(6.84 \%)$

$8(6.84 \%)$
$0.053 * *$

$0.097 * *$

$0.072 * *$

$0.077^{* *}$

Note: $p$-differences between groups; \#-for quantitative attributes according to the Mann-Whitney criterion; * for qualitative characteristics according to criterion $\chi^{2}$ of Pearson; **-for qualitative signs according to Fischer's exact criterion

The groups differed in the proportion of patients with acute stroke - in the group with AF, it was significantly $(\mathrm{p}=0.002)$ higher $-23.81 \%$, compared with $8.55 \%$ in the comparison group. Also, the differences were determined by angina - in the group without AF, the proportion of patients with coronary artery disease was higher and amounted to $58.97 \%$, whereas among patients with atrial fibrillation $-31.43 \%(\mathrm{p}<0.001)$. The difference is mainly due to discrepancies in the presence of angina of the 3rd functional class $-38.46 \%$ in the group without AF and $20.95 \%$ in the presence of atrial fibrillation $(\mathrm{p}=0.005)$. 
Table 2

Comorbidity in patients with ischemic heart disease, $\mathrm{n}(\%)$

\begin{tabular}{|c|c|c|c|c|}
\hline Disease & $\begin{array}{l}\text { Totally observed } \\
\qquad(\mathrm{n}=222)\end{array}$ & $\begin{array}{l}\text { Group with } A F \\
(n=105)\end{array}$ & $\begin{array}{l}\text { Group without } A F \\
\qquad(n=1117)\end{array}$ & $\mathbf{p}^{*}$ \\
\hline 1 & 2 & 3 & 4 & 5 \\
\hline \multicolumn{5}{|c|}{ Acute stroke, n (\%) } \\
\hline without acute stroke & $187(84.23 \%)$ & $80(76.19 \%)$ & $107(91.45 \%)$ & \multirow{2}{*}{0.002} \\
\hline with acute stroke & $35(15.77 \%)$ & $25(23.81 \%)$ & $10(8.55 \%)$ & \\
\hline \multicolumn{5}{|c|}{ ACS, n (\%) } \\
\hline without ACS & $176(79.28 \%)$ & $87(82.86 \%)$ & $89(76.07 \%)$ & \multirow{2}{*}{0.213} \\
\hline with ACS & $46(20.72 \%)$ & $18(17.14 \%)$ & $28(23.93 \%)$ & \\
\hline \multicolumn{5}{|c|}{ Angina pectoris, n (\%) } \\
\hline without angina pectoris & $120(54.05 \%)$ & $72(68.57 \%)$ & $48(41.03 \%)$ & \multirow{2}{*}{$<0.001$} \\
\hline with angina pectoris & $102(45.95 \%)$ & $33(31.43 \%)$ & $69(58.97 \%)$ & \\
\hline \multicolumn{5}{|c|}{ Functional class of angina pectoris, $\mathrm{n}(\%)$} \\
\hline 2 & $29(13.06 \%)$ & $11(10.48 \%)$ & $18(15.38 \%)$ & 0.279 \\
\hline 3 & $67(30.18 \%)$ & $22(20.95 \%)$ & $45(38.46 \%)$ & 0.005 \\
\hline 4 & $2(0.9 \%)$ & $0(0 \%)$ & $2(1.71 \%)$ & 0.534 \\
\hline \multicolumn{5}{|c|}{ Hypertension (HT), n (\%) } \\
\hline without hypertension & $24(10.81 \%)$ & $15(14.29 \%)$ & $9(7.69 \%)$ & \multirow{2}{*}{0.114} \\
\hline with hypertension & $198(89.19 \%)$ & $90(85.71 \%)$ & $108(92.31 \%)$ & \\
\hline \multicolumn{5}{|c|}{ Degree of HT, n (\%) } \\
\hline 2 & $131(59.01 \%)$ & $59(56.19 \%)$ & $72(61.54 \%)$ & 0.419 \\
\hline 3 & $67(30.18 \%)$ & $31(29.52 \%)$ & $36(30.77 \%)$ & 0.883 \\
\hline \multicolumn{5}{|c|}{ Stage of HT, n (\%) } \\
\hline 1 & $11(4.95 \%)$ & $8(7.62 \%)$ & $3(2.56 \%)$ & 0.083 \\
\hline 2 & $118(53.15 \%)$ & $57(54.29 \%)$ & $61(52.14 \%)$ & 0.749 \\
\hline 3 & $70(31.53 \%)$ & $25(23.81 \%)$ & $45(38.46 \%)$ & 0.019 \\
\hline \multicolumn{5}{|c|}{ Diabetes mellitus (DM), n (\%) } \\
\hline $\mathrm{n}$ & 211 & 102 & 109 & \multirow{3}{*}{0.564} \\
\hline without DM & $124(58.77 \%)$ & $62(60.78 \%)$ & $62(56.88 \%)$ & \\
\hline with DM & $87(41.23 \%)$ & $40(39.22 \%)$ & $47(43.12 \%)$ & \\
\hline \multicolumn{5}{|c|}{ Decrease of GFR, $\mathrm{n}(\%)$} \\
\hline $\mathrm{n}$ & 181 & 79 & 102 & \\
\hline without pathology & $54(29.83 \%)$ & $21(26.58 \%)$ & $33(32.35 \%)$ & \multirow{2}{*}{0.400} \\
\hline with pathology & $127(70.17 \%)$ & $58(73.42 \%)$ & $69(67.65 \%)$ & \\
\hline
\end{tabular}




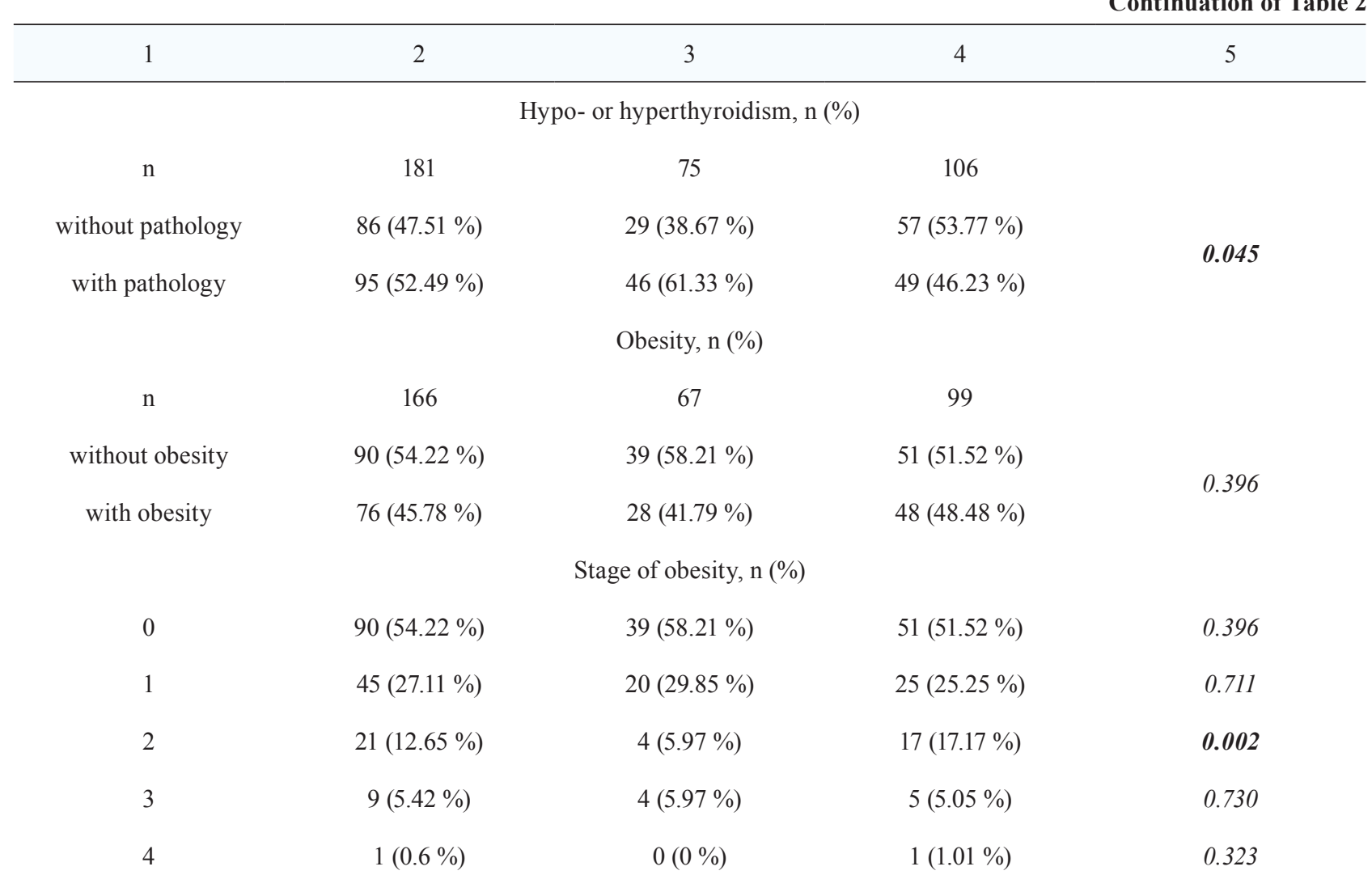

Diastolic disfunction (E/A<1), n (\%)

$\mathrm{n}$

$\begin{array}{cc}\text { without DD } & 62(43.36 \%) \\ \text { with DD } & 81(56.64 \%)\end{array}$
40

$31(77.5 \%)$

$9(22.5 \%)$
103

$31(30.1 \%)$

$72(69.9 \%)$

Note: ${ }^{*}-p$ is the difference between the groups according to Pearson's criterion $\chi^{2}$, including the Yeats correction

Patients with atrial fibrillation did not differ in the proportion of people with acute myocardial infarction - in general, $20.72 \%$ with a minor excess in the comparison group (23.93\% vs. $17.14 \%$ ), hypertension ( $92.31 \%$ in the group without AF, and $85.71 \%$ in the AF group), diabetes mellitus (43.12\% and 39.22\% respectively), kidney pathology (67.65\% and $73.42 \%$ respectively), obesity ( $48.48 \%$ and $41.79 \% \%$ respectively).

In the structure of the distribution according to the HT stage, there were no discrepancies regarding the stage of the disease, and then differences were observed only in the proportion of patients with 3rd stage HT, which was higher in the comparison group (38.46\% in the group without AF with $23.81 \%$ with atrial fibrillation).

It should be noted that there are significant differences $(p=0.002)$ between the groups in the proportion of patients with obesity of the 2nd stage - the proportion of such patients is greater in the group without AF (5.97\%), compared with the group with AF (17.17\%).

The proportion of patients with diastolic dysfunction (DD) in the group without AF is significantly higher $(69.9 \%)$ compared with the group without AF - $22.5 \%(p<0.001)$.

Thyroid dysfunction was found in the main group with a frequency of $61.33 \%$ (95\% CI $50.02-71.54)$, which is statistically significant $(\mathrm{p}<0.05)$ and can be compared more with the group without AF - 46.23\% (95\% CI 37.03-55.68). In addition to the thyroid pathology, in the main group, the frequency of GPMC was significantly higher $(\mathrm{p}<0.05)$, significantly lower - the frequency of angina and DD (Fig. 1). 
In the main study group, the incidence of concomitant pathology in the order of decline predominated: HT, kidney pathology and thyroid pathology; whereas in the comparison group - HT, diastolic dysfunction and kidney pathology. The last ranked place in the frequency of occurrence in the group with AF was acute myocardial infarction - $17.14 \%$ (95 \% CI 11.13-25.48), while in the comparison group, the penultimate one with a frequency of $23.93 \%$ (95\% CI 17, 11-32.41).

By rank correlation analysis, reliable $(p<0.05)$ inverse correlation bonds of mean strength of AF with diastolic dysfunction $(\rho=-0.43 ; p<0.001)$ were found; weak - with angina pectoris $(\rho=$ $=-0.28 ; \mathrm{p}<0.001)$ and degree of GC $(\rho=-0.20 ; p=0.003)$. Consequently, in the presence of these diseases, atrial fibrillation develops less frequently. Direct weak correlations were detected between AF and acute stroke $(\rho=0.21 ; p=0.002)$ and pathology of the thyroid gland $(\rho=0.15 ; p=0.045)$, therefore, atrial fibrillation develops more frequently in these pathologies.

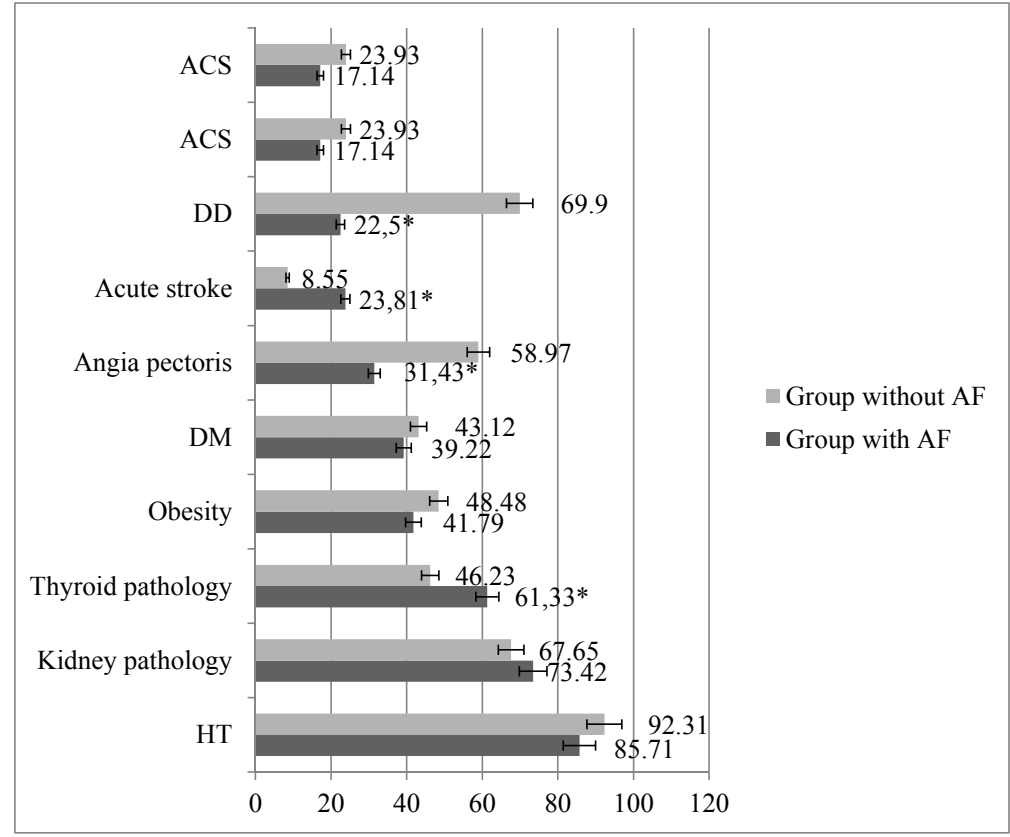

Fig. 1. Comorbidity in the examined patients with coronary artery disease, depending on the presence of atrial fibrillation $(\mathrm{P} \pm \mathrm{mr}, \%)$ : * ${ }^{*} \mathrm{p}<0.05$ compared with the group without AF by the Pearson $\chi^{2}$ criterion

\section{Discussion}

According to the results of numerous studies with age, increases the incidence of cardiovascular diseases such as hypertension, ischemic heart disease, heart failure, various cardiac arrhythmias, post-infarction cardiosclerosis [13, 15].

The results of the study are consistent with the literature, which indicates that the presence of atrial fibrillation also increases with age $[15,16]$. At the same time, according to modern ideas and results obtained, the incidence of atrial fibrillation and the frequency of comorbidity [17] increases with age, which greatly complicates the diagnosis and choice of therapeutic tactics when combined with a patient with comorbidity and atrial fibrillation [18].

Nowadays, there are data on the relationship between body mass and the development of cardiovascular disease [19]. Some studies indicate that patients with high body weight have lower mortality in patients with heart failure than patients with low body weight [9, 20]. According to the European guidelines, in the presence of atrial fibrillation, the mass of the body may be a predictor of its development [7, 21], which does not contradict the results. According to the study, the incidence rate of obesity was found to be rather high in both groups.

Identification at an early stage the diagnosis, the patient's risk factors and comorbid pathology is important for the primary prevention as well as for secondary prevention in order to prevent the development of repeated acute stroke, which often develop in this category of patients 
$[22,23]$. Development of individual practical recommendations for the diagnosis and treatment of atrial fibrillation in patients with ischemic heart disease, depending on the presence of comorbidity pathology [24], which is planned in the future, has a promising value in practice.

\section{Conclusions}

1. The presence of atrial fibrillation in patients with coronary heart disease is associated with a high degree of comorbidity that increases with age.

2. In case of combination IHD and atrial fibrillation was detected a high incidence of hypertension, diabetes mellitus, obesity, acute cardiovascular disorders, kidney disease and thyroid gland.

\section{References}

[1] Chugh, S. S., Havmoeller, R., Narayanan, K., Singh, D., Rienstra, M., Benjamin, E. J. et. al. (2014). Worldwide Epidemiology of Atrial Fibrillation: A Global Burden of Disease 2010 Study. Circulation, 129 (8), 837-847. doi: 10.1161/circulationaha.113.005119

[2] Oldgren, J., Healey, J. S., Ezekowitz, M., Commerford, P., Avezum, A. et. al. (2014). Variations in Cause and Management of Atrial Fibrillation in a Prospective Registry of 15400 Emergency Department Patients in 46 Countries: The RE-LY Atrial Fibrillation Registry. Circulation, 129 (15), 1568-1576. doi: 10.1161/circulationaha.113.005451

[3] Maggioni, A. P. (2015). Epidemiology of Heart Failure in Europe. Heart Failure Clinics, 11 (4), 625-635. doi: 10.1016/j.hfc.2015.07.015

[4] Schnabel, R. B., Yin, X., Gona, P., Larson, M. G., Beiser, A. S., McManus, D. D. et. al. (2015). 50 year trends in atrial fibrillation prevalence, incidence, risk factors, and mortality in the Framingham Heart Study: a cohort study. The Lancet, 386 (9989), 154-162. doi: 10.1016/s0140-6736(14)61774-8

[5] Vanassche, T., Lauw, M. N., Eikelboom, J. W., Healey, J. S., Hart, R. G., Alings, M. et. al. (2014). Risk of ischaemic stroke according to pattern of atrial fibrillation: analysis of 6563 aspirin-treated patients in ACTIVE-A and AVERROES. European Heart Journal, 36 (5), 281-288. doi: 10.1093/ eurheartj/ehu307

[6] Kuryata, O., Kushnir, Yu. (2014). Dynamics of aldosterone levels in patients with chronic heart failure with preserved ejection fraction under the influence of treatment. Meditsina-neotlozhnyh-sostoyani, 2, 57-62.

[7] January, C. T., Wann, L. S., Alpert, J. S., Calkins, H., Cigarroa, J. E., Cleveland, J. C. et. al. (2014). 2014 AHA/ACC/HRS Guideline for the Management of Patients With Atrial Fibrillation: A Report of the American College of Cardiology/American Heart Association Task Force on Practice Guidelines and the Heart Rhythm Society. Circulation, 130 (23), e199-e267. doi: 10.1161/cir.0000000000000041

[8] Healey, J. S., Connolly, S. J., Gold, M. R., Israel, C. W., Van Gelder, I. C., Capucci, A. et. al. (2012). Subclinical Atrial Fibrillation and the Risk of Stroke. New England Journal of Medicine, 366 (2), 120-129. doi: 10.1056/nejmoa1105575

[9] Kushnir, Yu. (2014). Hemodynamics, functional state of endothelium and renal function, platelets depending on the body mass index in patients with chronic heart failure and preserved systolic function. Medicni perspektivi, XIX (1), 29-36.

[10] Kuryata, O., Kushnir, Yu. (2014). Body mass and aldosteron, leptin levels in patients with chronic heart failure and preserved ejection fraction. Suchasni medichni tehnologii, 1, 12-16.

[11] Rebrova, O. (2006). Statistical analysis of medical data. Application of software package STATISTICA. Moscow: Mediasfera, 312.

[12] Rebrova, O. (2002). Statistical analysis of medical data. Application of software package STATISTICA. Moscow: MediaSfera, 312.

[13] Salamanca-Bautista, P., Conde-Martel, A., Aramburu-Bodas, O., Formiga, F., Trullas, J. C., Quesada-Simon, M. A. et. al. (2016). Precipitating factors of heart failure admission: Differences related to age and left ventricular ejection fraction. International Journal of Cardiology, 219, 150-155. doi: 10.1016/j. ijcard.2016.06.040 
[14] Fleg, J. L., Strait, J. (2011). Age-associated changes in cardiovascular structure and function: a fertile milieu for future disease. Heart Failure Reviews, 17 (4-5), 545-554. doi: 10.1007/s10741$011-9270-2$

[15] Kushnir, Yu. S., Kuryata, O. V., Dobrogorska, H. O. (2017). Cardiovascular diseases and comorbidity in patients with chronic heart failure and preserved ejection fraction depending on age. Simiina medycyna, 5 (73), 66-69.

[16] Mitrousi, K., Lip, G. Y. H., Apostolakis, S. (2013). Age as a Risk Factor for Stroke in Atrial Fibrillation Patients: Implications in Thromboprophylaxis in the Era of Novel Oral Anticoagulants. Journal of Atrial Fibrillation, 6 (1), 783.

[17] Rizos, T., Horstmann, S., Dittgen, F., Tager, T., Jenetzky, E., Heuschmann, P., Veltkamp, R. (2016). Preexisting Heart Disease Underlies Newly Diagnosed Atrial Fibrillation After Acute Ischemic Stroke. Stroke, 47 (2), 336-341. doi: 10.1161/strokeaha.115.011465

[18] Chen, X., Lin, M., Wang, W. (2017). The progression in atrial fibrillation patients with COPD: a systematic review and meta-analysis. Oncotarget, 8 (60), 102420-102427. doi: 10.18632/oncotarget. 22092

[19] Chang, V. W., Langa, K. M., Weir, D., Iwashyna, T. J. (2017). The obesity paradox and incident cardiovascular disease: A population-based study. PLOS ONE, 12 (12), e0188636. doi: 10.1371/journal. pone. 0188636

[20] Rizos, T., Horstmann, S., Dittgen, F., Tager, T., Jenetzky, E., Heuschmann, P., Veltkamp, R. (2016). Preexisting Heart Disease Underlies Newly Diagnosed Atrial Fibrillation After Acute Ischemic Stroke. Stroke, 47 (2), 336-341. doi: 10.1161/strokeaha.115.011465

[21] Sposato, L. A., Riccio, P. M., Hachinski, V. (2014). Poststroke atrial fibrillation: Cause or consequence?: Critical review of current views. Neurology, 82 (13), 1180-1186. doi: 10.1212/wnl.00000 00000000265

[22] Kamel, H., Okin, P. M., Elkind, M. S., Iadecola, C. (2016). Atrial fibrillation and mechanisms of stroke: time for a new model. Stroke, 47, 895-900. doi: 10.1161/strokeaha.115.012004

[23] Bridge, F., Thijs, V. (2016). How and When to Screen for Atrial Fibrillation after Stroke: Insights from Insertable Cardiac Monitoring Devices. Journal of Stroke, 18 (2), 121-128. doi: 10.5853/ jos.2016.00150

[24] Nattel, S., Harada, M. (2014). Atrial Remodeling and Atrial Fibrillation. Journal of the American College of Cardiology, 63 (22), 2335-2345. doi: 10.1016/j.jacc.2014.02.555 